University of Nebraska - Lincoln

DigitalCommons@University of Nebraska - Lincoln

\title{
Evaluation of Wheat Blended with Corn in Finishing Diets Containing Wet Distillers Grains
}

C A. Coulson

B M. Boyd

B B. Conroy

Galen E. Erickson

Follow this and additional works at: https://digitalcommons.unl.edu/animalscinbcr

Part of the Large or Food Animal and Equine Medicine Commons, Meat Science Commons, and the Veterinary Preventive Medicine, Epidemiology, and Public Health Commons

This Article is brought to you for free and open access by the Animal Science Department at DigitalCommons@University of Nebraska - Lincoln. It has been accepted for inclusion in Nebraska Beef Cattle Reports by an authorized administrator of DigitalCommons@University of Nebraska - Lincoln. 


\section{Evaluation of Wheat Blended with Corn in Finishing Diets Containing Wet Distillers Grains}

\section{A. Coulson \\ B. M. Boyd \\ B. B. Conroy \\ G. E. Erickson}

\section{Summary with Implications}

An experiment was conducted to evaluate the effect of grain type and wet distillers grains inclusion on finishing cattle performance and carcass characteristics. It was hypothesized that a greater inclusion of wet distillers grains would help mitigate acidosis previously observed with feeding wheat. Treatments were designed as a $2 \times 2$ factorial arrangement, with the first factor as grain type at either $100 \%$ dry rolled corn or a 50:50 blend of dry-rolled wheat and dryrolled corn, and the second factor as wet distillers grains plus solubles (WDGS) inclusion at either 12 or $30 \%$ of diet dry matter. There were no interactions between grain type and WDGS inclusion level. Increasing WDGS in the diet improved average daily gain and feed conversion and increased hot carcass weight. There was no performance or carcass trait response to grain type. Increasing the inclusion of WDGS in the diet improves performance regardless of grain type used. Contrary to the hypothesis, feeding dry-rolled corn or a blend of dry-rolled corn and dryrolled wheat performed similarly at different WDGS inclusions, and may be an economical replacement for corn during certain times of the year.

\section{Introduction}

Feeding dry-rolled wheat as a grain source in finishing diets is not a new concept, but its rapid ruminal fermentation can cause digestive disturbances, such as acidosis. However, in certain regions and months of the year, wheat may become an economically feasible option to replace corn as part of the diet for beef cattle. Much of

(c) The Board Regents of the University of Nebraska. All rights reserved.

Table 1. Diet composition (\% of diet DM) of corn or corn and wheat blended diets with two inclusions of WDGS.

\begin{tabular}{lccccc}
\hline Grain Type & DRC & DRC & & BLEND $^{1}$ & BLEND \\
\cline { 1 - 3 } \cline { 5 - 6 } WDGS Inclusion & 12 & 30 & & 12 & 30 \\
\hline DRC & 67 & 49 & & 33.5 & 24.5 \\
Wheat & 0 & 0 & & 33.5 & 24.5 \\
WDGS & 12 & 30 & & 12 & 30 \\
Corn Silage & 15 & 15 & & 15 & 15 \\
Supplement ${ }^{2}$ & 6 & 6 & & 6 & 6 \\
Urea & 1 & 0 & & 0.5 & 0 \\
Chemical Composition, \% & & & & 0.5 \\
$\quad$ Diet DM & 69.38 & 59.88 & & 70.65 & 60.89 \\
Crude Protein & 13.0 & 14.7 & & 13.0 & 15.7 \\
Ca & 0.76 & 0.77 & & 0.77 & 0.78 \\
P & 0.30 & 0.43 & & 0.35 & 0.47 \\
\hline
\end{tabular}

${ }^{1} 50: 50$ blend of DRC and wheat

${ }^{2}$ Liquid supplement was $68 \% \mathrm{DM}$ and formulated to provide: 0 or $1 \%$ urea, $10.9 \%$ calcium, $390 \mathrm{mg} / \mathrm{hd} / \mathrm{d}$ monensin, and $83 \mathrm{mg} /$ hd/d tylosin.

the previous work on feeding wheat as part of the diet was done prior to the widespread use of distillers grains in the diet. Many Nebraska feedlots are feeding some level of distillers grains, but performance advantages suggest that yards should be feeding at least $12 \%$ but no more than $40 \%$ WDGS (DM-basis) as part of the diet. Perhaps, feeding more readily fermentable starch from wheat with $30 \%$ WDGS will mitigate acidosis concerns and increase performance compared to lower WDGS levels, such as $12 \%$. Therefore, the objective of this experiment was to compare DRC-based or a 50:50 blend of DRC and wheat-based diets with either 12 or $30 \%$ WDGS (DM-basis) on finishing cattle performance and carcass characteristics.

\section{Procedure}

A feedlot study was conducted at the University of Nebraska-Lincoln Panhandle Research and Extension Center (PREC), Scottsbluff, NE. Crossbred steers $(n=320$; initial $\mathrm{BW}=716 \pm 50 \mathrm{lb}$ ) were used in a 2 $\times 2$ factorial treatment design with factors consisting of two grain types [dry-rolled corn (DRC) or dry-rolled corn/dry-rolled wheat blend (BLEND)] and two inclusions of wet distillers grains (WDGS) levels (12 or $30 \%$ DM-basis or $22.1 \%$ or $45.8 \%$ asfed). Corn silage was used as the roughage source in all diets (Table 1). A liquid supplement was fed with either $0 \%$ or $1 \%$ of urea. The $1 \%$ urea supplement was used in the dry-rolled corn with $12 \%$ WDGS diet. A 50:50 blend of the $0 \%$ and $1 \%$ urea supplement was used in the corn-wheat blend with 12\% WDGS diet to target $0.5 \%$ urea in the diet. No urea was added to diets containing $30 \%$ WDGS. Wheat was processed on-site using a roller mill (Automatic Ag, Pender, NE) and corn was processed using a commercial roller mill throughout the feeding study. All cattle were limit fed a common diet consisting of $30 \%$ alfalfa hay, $40 \%$ corn silage, $25 \%$ WDGS, and $5 \%$ supplement (DM-basis) for 5 consecutive days to minimize $B W$ variation due to gut 
Table 2. Effect of feeding DRC or 50:50 blend of DRC on steer performance and carcass characteristics.

\begin{tabular}{|c|c|c|c|c|}
\hline Grain Type & DRC & BLEND & SEM & $\begin{array}{c}\text { Grain Type } \\
\text { P-Value }\end{array}$ \\
\hline Initial BW & 716 & 716 & 0.7 & 0.95 \\
\hline \multicolumn{5}{|l|}{ Live Performance } \\
\hline Final BW & 1352 & 1357 & 6.9 & 0.58 \\
\hline DMI, lb/d & 23.9 & 24.3 & 0.29 & 0.29 \\
\hline $\mathrm{ADG}, \mathrm{lb}$ & 4.02 & 4.06 & 0.042 & 0.56 \\
\hline$F: G^{1}$ & 5.92 & 5.99 & - & 0.59 \\
\hline \multicolumn{5}{|c|}{ Carcass Adj. Performance } \\
\hline Final BW ${ }^{2}$ & 1325 & 1327 & 7.6 & 0.84 \\
\hline $\mathrm{ADG}, \mathrm{lb} / \mathrm{d}$ & 3.85 & 3.87 & 0.048 & 0.81 \\
\hline $\mathrm{F}: \mathrm{G}^{1}$ & 6.17 & 6.29 & - & 0.43 \\
\hline \multicolumn{5}{|l|}{ Carcass Characteristics } \\
\hline $\mathrm{HCW}, \mathrm{lb}$ & 835 & 836 & 4.8 & 0.84 \\
\hline Dressing \% & 61.8 & 61.6 & 1.7 & 0.53 \\
\hline REA, in ${ }^{2}$ & 13.1 & 13.5 & 0.087 & 0.02 \\
\hline 12th rib fat, in. & 0.52 & 0.50 & 0.012 & 0.36 \\
\hline Marbling Score ${ }^{3}$ & 533 & 511 & 10.7 & 0.15 \\
\hline Calculated $\mathrm{YG}^{4}$ & 3.27 & 3.13 & 0.049 & 0.04 \\
\hline Liver Abscess, $\%$ & 13.3 & 14.2 & 3.9 & 0.61 \\
\hline
\end{tabular}

${ }^{1}$ Analyzed as its reciprocal, G:F

${ }^{2} \mathrm{HCW}$ adjusted to a common dressing percent of $63 \%$

${ }^{3} 400=$ small, $500=$ modest, $600=$ moderate

${ }^{4}$ Calculated using the following equation: $2.5+\left(2.5^{*} 12^{\text {th }}\right.$ rib fat thickness, in. $)-\left(0.32^{*} \mathrm{LM}\right.$ area, in $\left.{ }^{2}\right)+\left(0.2^{*} 2.5 \mathrm{KPH}\right)+$ $\left(0.0038^{*} \mathrm{HCW}, \mathrm{lb}\right)(\mathrm{USDA}, 2016)$

fill. Cattle were fed once daily and provided ad libitum access to feed and water. All cattle were stepped up to their respective diet over $23 \mathrm{~d}$ with concentrate (corn and/or wheat) replacing alfalfa hay and corn silage ( $25 \%$ and $40 \%$, respectively, for alfalfa hay and corn silage initially). The finishing diet is presented in Table 1. Cattle were weighed two consecutive days to establish initial BW. Three blocks were used with two reps in the light block, four reps in the middle block, and two reps in the heavy block for 32 total pens with 8 replications per treatment $(10$ steers/pen).

Cattle were implanted with Revalor-XS (200 mg trenbolone acetate $+40 \mathrm{mg}$ estradiol; Merck Animal Health) on d 1. Steers were fed for 158 days and harvested at a commercial abattoir (Greater Omaha Packing, Omaha, NE). On the day of shipping, steers were weighed in the morning, loaded,
Block, grain type and WDGS inclusion were considered fixed effects. Liver data were analyzed using the GLIMMIX procedure of SAS as a binomial distribution. Alpha values $\leq 0.05$ were considered significant and $0.05 \leq a \leq 0.10$ is considered a tendency.

\section{Results}

There were no significant interactions between grain type or WDGS inclusion $(P \geq 0.21)$. Average daily gain was 3.80 , 3.91, 3.78 and $3.96 \mathrm{lb} / \mathrm{d}$ and F:G was 6.29 , 6.06, 6.41 and 6.13 for DRC12, DRC30, BLEND12 and BLEND30, respectively. The hypothesis that wheat blended with corn would result in better gain and feed conversion in diets with $30 \%$ WDGS compared to $12 \%$ WDGS was not correct. Due to the lack of an interaction of grain type and WDGS inclusion, only main effects will be discussed. There were no differences in live or carcass-adjusted final BW, ADG, DMI, or feed conversion $(P \geq 0.29$; Table 2) between $100 \%$ DRC or 50:50 blend of DRC and wheat. Geometric mean diameter of DRC was $3814 \mu \mathrm{m}(\mathrm{SD}=1201 \mu \mathrm{m})$ and DRW was $2258 \mu \mathrm{m}(\mathrm{SD}=432 \mu \mathrm{m})$. These data suggest that up to $50 \%$ wheat can be fed as the grain portion of the diet resulting in no change in performance.

Steers that were fed $30 \%$ WDGS were 24 lbs heavier $(P=0.03$; Table 3$)$ at slaughter as compared to steers fed $12 \%$ WDGS. Cattle fed 30\% WDGS had improved ADG by $3.8 \%(P=0.03)$ and were $3.8 \%$ more efficient $(P=0.05)$ than steers fed $12 \%$ WDGS regardless of grain type.

There were no significant interactions between grain type and WDGS inclusion $(P$ $\geq 0.32$ ) for carcass characteristics, therefore, only the main effects of grain type and WDGS inclusion will be presented. There was no difference in HCW or dressing percent $(P \geq 0.53$; Table 2$)$ for steers fed $100 \%$ DRC or 50:50 blend of DRC and wheat. Longissimus muscle area was significantly greater $(P=0.02)$ for steers fed 50:50 blend of DRC and wheat compared to steers only fed DRC. No differences were observed in $12^{\text {th }}$ rib fat or USDA marbling score between grain type $(P \geq 0.15)$, but with the increase in LM area, cattle fed the blended diet had an improved calculated yield grade $(P=0.04)$. It is important to note that this 
Table 3. Effect of WDGS inclusion level on performance and carcass characteristics of finishing steers.

\begin{tabular}{|c|c|c|c|c|}
\hline WDGS Inclusion & 12 & 30 & SEM & WDGS Incl. P-Value \\
\hline Initial BW & 719 & 719 & 0.7 & 0.51 \\
\hline \multicolumn{5}{|l|}{ Live Performance } \\
\hline Final BW & 1345 & 1364 & 6.9 & 0.06 \\
\hline DMI, lb & 24.1 & 24.1 & 0.29 & 0.93 \\
\hline $\mathrm{ADG}, \mathrm{lb} / \mathrm{d}$ & 3.98 & 4.10 & 0.043 & 0.07 \\
\hline $\mathrm{F}: \mathrm{G}^{1}$ & 6.02 & 5.88 & - & 0.07 \\
\hline \multicolumn{5}{|c|}{ Carcass Adj. Performance } \\
\hline Final BW² & 1314 & 1338 & 7.6 & 0.03 \\
\hline $\mathrm{ADG}, \mathrm{lb} / \mathrm{d}$ & 3.79 & 3.94 & 0.048 & 0.03 \\
\hline $\mathrm{F}: \mathrm{G}^{1}$ & 6.37 & 6.10 & - & 0.05 \\
\hline \multicolumn{5}{|l|}{ Carcass Characteristics } \\
\hline $\mathrm{HCW}, \mathrm{lb}$ & 828 & 843 & 4.8 & 0.03 \\
\hline Dressing \% & 61.6 & 61.8 & 1.7 & 0.28 \\
\hline REA, in ${ }^{2}$ & 13.2 & 13.4 & 0.09 & 0.13 \\
\hline 12th rib fat, in. & 0.49 & 0.53 & 0.013 & 0.02 \\
\hline Marbling Score ${ }^{3}$ & 531 & 513 & 10.7 & 0.24 \\
\hline Calculated $\mathrm{YG}^{4}$ & 3.14 & 3.26 & 0.049 & 0.09 \\
\hline Liver Abscess, $\%$ & 11.3 & 12.7 & 3.5 & 0.42 \\
\hline
\end{tabular}

${ }^{1}$ Analyzed as its reciprocal, G:F

${ }^{2} \mathrm{HCW}$ adjusted to a common dressing percent of $63 \%$

${ }^{3} 400=$ small $00 ; 500=$ modest $00 ; 600=$ moderate 00

${ }^{4}$ Calculated using the following equation: $2.5+\left(2.5^{\star} 12^{\text {th }}\right.$ rib fat thickness, in. $)-\left(0.32^{\star} \mathrm{LM}\right.$ area, in $\left.{ }^{2}\right)+\left(0.2^{\star} 2.5 \mathrm{KPH}\right)+$ $\left(0.0038^{*} \mathrm{HCW}, \mathrm{lb}\right)$ (USDA, 2016) was a heavily replicated study (16 replications per main effect) and therefore, small changes were statistically significant and may not be explained biologically.

Steers fed 30\% WDGS had heavier HCW $(P=0.03$; Table 3$)$, had greater $12^{\text {th }}$ rib fat $(P=0.02)$, and tended to have poorer yield grade $(P=0.09)$ compared to cattle fed 12\% WDGS. There were no differences between WDGS inclusions for dressing percent, LM area, or USDA marbling score $(P \geq 0.13)$.

\section{Conclusion}

Overall, there was no interaction between grain type (DRC or 50:50 blend DRC and wheat) and WDGS inclusion (12 or $30 \% \mathrm{DM}$ basis) for cattle performance or carcass characteristics. There was a significant response for cattle fed 30\% WDGS compared to $12 \%$ WDGS, but there was no performance response for grain type. Feeding a 50:50 blend of DRC and wheat resulted in an increase in LM area and no change in other carcass characteristics, leading to a more desirable calculated YG. Greater inclusions of WDGS (30\%) resulted in greater $\mathrm{HCW}$ and $12^{\text {th }}$ rib fat but tended to increase calculated YG compared to feeding $12 \%$ WDGS. There were minimal effects to feeding DRC compared to a 50:50 blend of DRC and wheat, but there was a performance and carcass response to feeding more WDGS. Therefore, the data suggest that if the price of wheat is competitive or less than that of corn, wheat can replace up to $50 \%$ of corn in the diet, regardless of WDGS inclusion, without an effect on performance.

Caitlin A. Coulson, graduate student

Bradley M. Boyd, research technician

Bri B. Conroy, feedlot manager

Galen E. Erickson, professor, Lincoln 